\title{
PRODUÇÃO DE MATERIAL DIDÁTICO PARA EDUCAÇÃO A DISTÂNCIA: PLANEJAMENTO E DIREITOS AUTORAIS*
}

\author{
REGIANE MARIA TOMÉ FAIM
}

\begin{abstract}
RESUMO
Este artigo objetiva discorrer sobre a produção de materiais didáticos para Educação a Distância (EaD) considerando o planejamento pedagógico e os direitos autorais. O método da investigação inclui análise bibliográfica dos principais teóricos sobre o tema como: Azevedo (2013), Behar (2009), Clementino (2015), Filatro e Cairo (2015), Ricardo (2012), Silva (2011, 2013),que viabilizaram discussões que podem e devem continuar a ser o objetivo maior dos profissionais que atuam ou venham atuar na EaD. Presume-se que tais reflexões poderão contribuir para aprimorar a prática docente na modalidade a distância, estimulando a busca de novas metodologias para a melhoria no processo de ensino-aprendizagem.
\end{abstract}

Palavras-chave: Educação a Distância; Planejamento; Material Didático.

\begin{abstract}
This article aims to discuss the production of didactic materials for distance education (DE) considering pedagogical planning and copyright. The research method includes a bibliographical analysis of the main theorists on the theme as: Azevedo (2013),
\end{abstract}

* Este artigo é fragmento do segundo capítulo da pesquisa de Mestrado realizada no Programa de Pós-Graduação em Educação da Universidade Metodista de São Paulo, intitulada "Planejamento, elaboração e utilização de materiais didáticos disponibilizados em ambiente virtual de aprendizagem", defendida no ano de 2018, com a orientação da Profa. Dra. Adriana Barroso de Azevedo. 
Behar (2009), Clementino (2015), Filatro and Cairo (2015), Ricardo (2013), Silva $(2011,2013)$ that enabled discussions which can and should continue to be the main objective of professionals who work or who will work in the DE. It is presumed that such reflections could contribute to improve the teaching practice in the distance modality, stimulating the search for new methodologies for the improvement of the teaching-learning process.

Keywords: Distance Education; Planning; Didactic Material.

\section{INTRODUÇÃO}

A organização de um curso na modalidade a distância exige conhecimentos e comprometimento no exercício da profissão docente, com a construção de saberes específicos para a elaboração de aulas e o gerenciamento do ambiente virtual de aprendizagem. Tais aspectos exigem domínio sobre os conteúdos teóricos e também a respeito das dimensões política, ética, humana, estética e técnica da matriz curricular de um curso.

Os saberes necessários à prática educativa contribuem para um processo de conscientização no qual se constituem ações pedagógicas. É necessário “entender a prática educativa como um exercício constante em favor da produção e do desenvolvimento da autonomia de educadores e educandos" (FREIRE, 1996, p. 145). Portanto, faz-se necessário entender a educação como um processo realizado por seres em construção, que aprendem mutuamente.

Nessa amplitude das ações docentes, um curso na modalidade a distância demanda mudanças de prática no que diz respeito ao planejamento das aulas e tarefas, as quais se resumem, segundo Aretio (2002, apud AZEVEDO, 2013, p.157) em:

...ser especialista no conteúdo das disciplinas do curso, na produção dos materiais didáticos e ser responsável por guiar a aprendizagem por meio da tutoria ou do aconselhamento. Importante é que tais tarefas não são necessariamente realizadas pelo mesmo docente, daí o caráter de autoria coletiva que assume o processo educacional. 
Diante das alterações nas formas de conceber o ensino e produzir conhecimento ou lidar com a informação de fácil acesso, algumas instituições e profissionais de ensino passaram a refletir sobre processos educativos e a forma como são organizadas e planejadas as aulas, os módulos, os cursos e o ensino no ambiente virtual de aprendizagem (AVA). Afinal, as Tecnologias Digitais de Informação e Comunicação (TDIC) nos provocam a lidar com um espaço e tempo pedagógico global.

Assim, discutir sobre o planejamento, elaboração e utilização de materiais didáticos disponibilizados em ambiente virtual de aprendizagem torna-se necessário para todo professor que se propõe a trabalhar nessa modalidade.

\section{PLANEJAMENTO PEDAGÓGICO PARA CURSOS EAD}

A maior parte do tempo o ser humano vive planejando as ações presentes no seu cotidiano, seja no âmbito pessoal ou no profissional, pensando sobre o presente, o passado e o futuro que move sua vida. Nesse sentido, percebe-se que "o ato de pensar, portanto, é um ato de planejar” (CLEMENTINO, 2015, p. 151).

$\mathrm{Na}$ educação "o planejamento remete a ações previamente organizadas para responder aos desafios de aprendizagem, estabelecendo antecipadamente caminhos que norteiam a execução, o acompanhamento e a avaliação do processo educacional" (FILATRO; CAIRO, 2015, p. 225), levando em conta que os conteúdos educacionais são planejados por professores que se encontram separados, geograficamente e temporalmente, dos alunos.

Behar (2009, p. 180) compreende que "o planejamento é uma atividade intrínseca à didática e à prática docente. $\mathrm{O}$ planejamento é considerado o elemento orientador que guiará a realização do trabalho docente no processo educativo". Enquanto os Referenciais de Qualidade para Educação Superior a Distância (MINISTÉRIO DA EDUCAÇÃO, 2007, p. 9) reforçam

...a importância da educação superior ser baseada em um projeto pedagógico e em uma organização curricular inovadora, que favoreçam a integração entre os conteúdos e suas 
metodologias, bem como o diálogo do estudante consigo mesmo (e sua cultura), com os outros (e suas culturas) e com o conhecimento historicamente acumulado.

$\mathrm{Na} \mathrm{EaD}$, ao entender o planejamento pedagógico como a espinha dorsal de um curso, que parte da organização curricular e da definição de sua concepção sobre o ensinar e aprender, deve-se levar em conta "o cuidado e o compromisso da instituição para com o processo de ensino aprendizagem e, consequentemente, para com os alunos" (CLEMENTINO, 2015, p. 153).

Ainda, segundo os Referencias de Qualidade “o Material Didático, tanto do ponto de vista da abordagem do conteúdo, quanto da forma, deve estar concebido de acordo com os princípios epistemológicos, metodológicos e políticos explicitados no projeto pedagógico" (MINISTÉRIO DA EDUCAÇÃO, 2007, p. 13-14) observa

...que somente a experiência com cursos presenciais não é suficiente para assegurar a qualidade da produção de materiais adequados para a educação a distância. (...) é necessário que os docentes responsáveis pela produção dos conteúdos trabalhem integrados a uma equipe multidisciplinar, contendo profissionais especialistas em desenho instrucional, diagramação, ilustração, desenvolvimento de páginas web, entre outros.

Ademais, todos esses profissionais precisam considerar alguns aspectos no momento do planejamento pedagógico, conforme Haidt (2004, apud CLEMENTINO, 2015, p. 153-154) e

...tentar prever as dificuldades que podem surgir no curso, evitar a repetição rotineira e mecânica de aulas, adequar o trabalho às mídias disponíveis e às características dos alunos, adequar os conteúdos, as estratégias pedagógicas e as avaliações aos objetivos do curso, garantir a distribuição adequada do trabalho em relação ao tempo do curso. 
No âmbito da produção de conteúdos educacionais o foco do planejamento está no produto resultante, ou seja, nos "livros impressos e digitais, objetos de aprendizagem, podcasts, vídeos e infográficos, entre outras soluções educacionais. Cada um desses artefatos produzidos com finalidade educacional pode ser em si mesmo o objeto do planejamento" (FILATRO; CAIRO, 2015, p. 225, grifo das autoras).

No mapa mental a seguir apresenta-se a definição de planejamento pedagógico segundo Clementino (2015, p. 154) e as etapas desenvolvidas durante o processo, lembrando "que está sempre em construção. Para efeito didático, esse processo é dividido em etapas que devem ser inter-relacionadas".

\section{Mapa mental: Etapas do planejamento pedagógico para curso EaD}
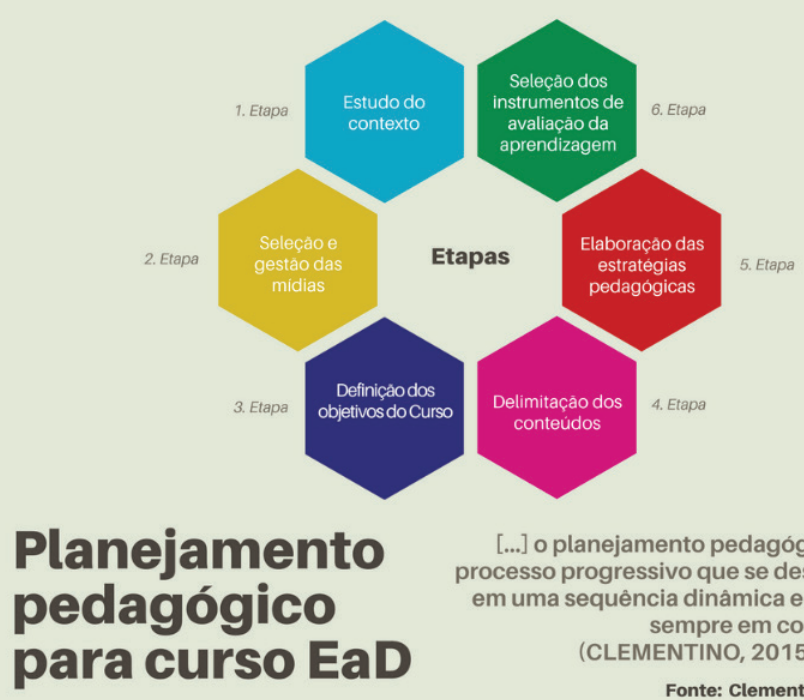

[...] o planejamento pedagógico é um processo progressivo que se desenvolve em uma sequência dinâmica e que está sempre em construção (CLEMENTINO, 2015, p. 154). Fonte: Clementino (2015)

Fonte: Elaborado pela autora baseado em Clementino (2015)

Na primeira etapa - estudo do contexto - a ênfase apresenta-se no diagnóstico da realidade do aluno, ou seja, 
na caracterização dos seus interesses e de suas necessidades. Segundo os Referenciais de Qualidade para Educação Superior a Distância (MINISTÉRIO DA EDUCAÇÃO, 2007, p. 7) “a natureza do curso e as reais condições do cotidiano e necessidades dos estudantes são os elementos que irão definir a melhor tecnologia e metodologia a ser utilizada ...".

A escolha da mídia para realização de um curso EaD presente na segunda etapa - seleção e gestão das mídias - pode modificar a forma como serão planejados e disponibilizados os materiais didáticos no AVA, pois depende da organização da equipe, do custo estimado pela instituição para infraestrutura tecnológica, da garantia do funcionamento das mídias durante todo curso e também do nível de interação entre os participantes, pensando nos profissionais que irão acompanhar as discussões e dar suporte (CLEMENTINO, 2015).

Clementino (2015) destaca que a etapa seguinte - definição dos objetivos do curso -influencia diretamente nas demais etapas do planejamento, pois trata-se do que se pretende alcançar em uma ação educativa e expressa a inter-relação entre os elementos do currículo. Nessa etapa são apresentados tanto os objetivos gerais, que contemplam a finalidade do curso, quanto aos objetivos específicos que, segundo Haidt (2004, apud CLEMENTINO, 2015, p. 172), auxiliam o professor a:

- definir os conteúdos a serem trabalhados no curso, determinando os conhecimentos e conceitos a serem adquiridos e as competências e habilidades a serem desenvolvidas pelo aluno;

- estabelecer estratégias de ensino-aprendizagem de maneira a privilegiar as atividades e experiências mais relevantes a serem vivenciadas pelos alunos;

- definir os modos de avaliação construindo os instrumentos mais adequados para avaliar o que se pretende;

- comunicar de modo claro e preciso os propósitos do curso/disciplina aos alunos. 
Para a quarta etapa - delimitação dos conteúdos - identifica-se a base teórica do curso para produção dos conhecimentos previstos, focando na preservação da neutralidade do material pelo professor. Alguns critérios precisam ser considerados: validade, utilidade, significação, adequação ao nível de desenvolvimento do aluno e flexibilidade. Outro aspecto determinante é a adequação do conteúdo selecionado à carga horária do curso (CLEMENTINO, 2015).

Filatro e Cairo (2015, p. 283) destacam que:

O levantamento de fontes bibliográficas e outros materiais de consulta é uma das primeiras ações realizadas pelo especialista em conteúdo. As fontes podem incluir:

- Materiais didáticos desenvolvidos pelo próprio especialista.

- Livros, artigos, enciclopédias e compêndios.

- Sites da web.

- Tutoriais, jogos, apostilas.

- Manuais de instrução de equipamentos, ferramentas e recursos.

- Folhetos materiais de divulgação etc.

A penúltima etapa do planejamento - elaboração das estratégias pedagógicas - ou metodologia de ensino-aprendizagem, corresponde ao momento de escolher como serão apresentados e trabalhados os conteúdos, com ênfase na necessidade de que os alunos alcancem os objetivos educacionais do curso (CLEMENTINO, 2015).

Segundo Clementino (2015, p. 180),

Como resumo, pode-se afirmar que nesse termo se incluem todas as atividades que serão propostas ao aluno (questões de múltipla escolha, fórum, chat, web conferência, trabalhos em grupo, atividades de pesquisa, etc.), as maneiras de apresentar o conteúdo (textos, vídeos, aulas narradas, etc.) e as ações do professor tutor que serão necessárias para 
complementar, organizar e/ou sintetizar as atividades dos alunos, tendo em vista a aprendizagem deles.

Para escolha das estratégias os profissionais devem ter bom senso, pois são os meios facilitadores para que os alunos alcancem os objetivos do curso. E o "excesso de recursos midiáticos para apresentar o conteúdo e excesso de atividades podem gerar confusão para o aluno e, por consequência, prejudicar o seu processo de aprendizagem" (CLEMENTINO, 2015, p. 181).

Enfim, na sexta etapa - seleção dos instrumentos de avaliação da aprendizagem-destacam-se,entre os documentos oficiais, os parâmetros que devem ser considerados pelas instituições de ensino quanto à avaliação. A Resolução n ${ }^{\circ}$ 1/2016, em seu parágrafo $3^{\circ}$, Art. $3^{\circ}$, Capítulo II, prevê que "os sistemas de acompanhamento e avaliação da aprendizagem devem ser contínuos e efetivos, visando propiciar, a partir da garantia de condições adequadas, o desenvolvimento e a autonomia do estudante no processo de ensino e aprendizagem" (MINISTÉRIO DA EDUCAÇÃO, 2016).

O Decreto n ${ }^{\circ} 9.057 / 2017$, em seu Art. $4^{\circ}$ (BRASIL, 2017), estabelece:

As atividades presenciais, como tutorias, avaliações, estágios, práticas profissionais e de laboratório e defesa de trabalhos, previstas nos projetos pedagógicos ou de desenvolvimento da instituição de ensino e do curso, serão realizadas na sede da instituição de ensino, nos polos de educação a distância ou em ambiente profissional, conforme Diretrizes Curriculares Nacionais.

Também consta nos Referenciais de Qualidade (MINISTÉRIO DA EDUCAÇÃO, 2007, p. 16) que “o modelo de avaliação de aprendizagem deve ajudar a desenvolver graus mais complexos de competências cognitivas, habilidades e atitudes, possibilitando alcançar os objetivos propostos".

Assim, vale salientar que diferentes tipos de avaliações e suas múltiplas funcionalidades podem ocorrer na EaD, como 
avaliação somativa, diagnóstica, formativa, etc., sendo que "o conceito de avaliação adotado em determinado projeto educacional está diretamente relacionado à visão de educação que a instituição possui" (CLEMENTINO, 2015, p. 184).

$\mathrm{Na}$ avaliação somativa a preocupação está na nota atribuída nas provas e/ou atividades realizadas pelos alunos. Já na avaliação diagnóstica considera-se a nota das atividades segundo as especificidades dos alunos, sua participação colaborativa nos grupos e sua vida escolar, partindo sempre da aplicação de um instrumento diagnóstico no início do curso. A avaliação formativa ocorre processualmente, ao longo das atividades realizadas pelo aluno, possibilitando ao professor fazer as correções e dar o feedback, o que auxilia no desenvolvimento do aluno durante o período do curso (CLEMENTINO, 2015).

Nesse sentido, de acordo com Filatro e Cairo (2015, p. 424)

...ganham espaço também instrumentos de avaliação como portfólios e portfólios eletrônicos (uma coletânea de trabalhos de alunos que demonstra o desenvolvimento de competências durante o processo de aprendizagem), autoavaliação, avaliação entre pares, para citar alguns. Observa-se que o foco está na produção dos alunos ao longo de um processo, rumo ao alcance dos objetivos educacionais, mais que na produção de terceiros visando a apoiar essa aprendizagem.

Pode-se verificar que a avaliação de um curso EaD deve ser coerente com as características do modelo adotado pela instituição, com o perfil do público-alvo, a sistematização adequada de instrumentos avaliativos que explorem as funcionalidades do ambiente virtual de aprendizagem, etc.

$\mathrm{Na}$ seção seguinte, o olhar se volta para questões relacionadas à produção de material didático e direitos autorais.

\section{PRODUÇÃO DE MATERIAL DIDÁTICO E DIREITOS AUTORAIS}

A Educação a Distância caracteriza-se como uma modalidade na qual possui especificidades em seu contexto educativo. 
O Cap. II, Art. $3^{\circ}$ da Resolução No 1/2016 (MINISTÉRIO DA EDUCAÇÃO, 2016) dispõe sobre o material didático, a avaliação e o acompanhamento da aprendizagem; regulamenta como essencial a organização acadêmica e a gestão de seus cursos articulada às metodologias e os currículos na orientação, organização e elaboração dos materiais didáticos; também discorre sobre o acompanhamento do processo de avaliação e formação dos profissionais (professores, gestores, tutores e equipe multidisciplinar), definindo:

$\int 1^{\circ}$ As tecnologias, as metodologias e os recursos educacionais, materializados em ambiente virtual multimídia interativo, inclusive materiais didáticos, bem como os sistemas de acompanhamento e de avaliação de aprendizagem, são elementos constitutivos dos cursos superiores na modalidade EaD...

$\int 4^{\circ}$ Respeitados os respectivos projetos institucionais e pedagógicos, as tecnologias, as metodologias e os recursos educacionais para a educação a distância devem favorecer a integração de diferentes mídias, suportes e linguagens, bem como a interação entre múltiplos atores em sua concepção, produção e disseminação.

$\int 5^{\circ}$ A definição do uso das tecnologias pretendidas e adotadas pela IES (internet, rádio, transmissões via satélite, entre outros) deve estar em consonância com a realidade da sede e do(s) polo(s) de EaD.

Diante dessas colocações, os Referenciais de Qualidade para a Educação Superior a Distância (MINISTÉRIO DA EDUCAÇÃO, 2007, p.14) recomendam que

....as instituições elaborem seus materiais para uso a distância, buscando integrar as diferentes mídias, explorando a convergência e integração entre materiais impressos, radiofônicos, televisivos, de informática, de videoconferências e teleconferências, dentre outros, sempre na perspectiva da 
construção do conhecimento e favorecendo a interação entre os múltiplos atores.

Silva (2013, p. 67) levanta algumas questões que precisam ser consideradas pelas instituições de ensino:

O material didático reflete a filosofia educacional adotada pela instituição.

- A quem cabe a produção do material? Equipe própria ou terceirizada?

- Qual design instrucional será utilizado para a produção?

- Que padrões de qualidade serão adotados?

- Os materiais didáticos são adequados à mídias e tecnologias adotadas?

- Possibilitam interação e interatividade?

Partindo dessas questões há certos caminhos que devem ser percorridos para a produção de conteúdos, no sentido de desenvolver recursos didáticos que se fundamentam na fonte do levantamento curricular inicial. As instituições cientes das exigências legais para a oferta e condução de seus cursos procuram, de início, orientar seus professores para a produção de materiais originais e vinculados às suas aulas, de forma a compor e constituir um acervo por área de conhecimento, podendo garantir uma identidade institucional aos materiais produzidos.

Esses materiais podem ter algumas origens, entre elas ajustes dos materiais utilizados no presencial ou produção de materiais especialmente para a modalidade EaD (SILVA, 2013), ou seja, sendo estruturados por textos, imagens e/ou diversas mídias tornam-se elementos que podem ou não apresentar autoria pelos professores.

Em conformidade com Filatro e Cairo (2015, p. 109):

Por vezes, esses materiais são preparados por iniciativa individual de professores ou especialistas, que buscam enriquecer suas aulas teóricas e práticas. Em outras situações, temos ações sistêmicas encabeçadas por equipes multidis- 
ciplinares que trabalham juntas para produzir materiais bem estruturados e compartilhados por vários educadores e alunos.

Para complementar, recorre-se às reflexões de Behar (2009, p. 27): "para seleção do conteúdo, por parte do curso e/ou professor, é preciso também levar em conta o design deste tipo de material, se une fatores técnicos, gráficos e pedagógicos, se é motivador (ou não) para o aluno, se é interativo, entre outros aspectos". Todos esses recursos digitais aparecem como ferramentas capazes de potencializar e reestruturar as práticas pedagógicas, possibilitando novas maneiras de pensar as TDIC e a construção do conhecimento.

Lembrando que a utilização da tecnologia pela tecnologia não é suficiente para a produção de materiais, "a ideia central é que o material elaborado simule a apresentação de conteúdos e a proposição de atividades de aprendizagem feitas por um educador a seus alunos, antecipadamente o diálogo didático que ocorreria em uma situação de ensino-aprendizagem convencional" (FILATRO; CAIRO, 2015, p. 286).

Filatro e Cairo (2015, p. 61) citam

Aretio $^{1}$ que chama de diálogo didático a interação dialógica que ocorre entre os atores do processo de ensino-aprendizagem, incluindo-se não apenas alunos e docentes, mas também equipe pedagógica e administrativa da instituição e, ainda interlocutores externos, como pais e responsáveis, empregadores e potenciais empregadores, profissionais da área, representantes do governo e toda a comunidade.

Nesse momento, torna-se relevante perceber que o diálogo didático pode ocorrer de duas maneiras: real ou simulado. No caso do diálogo didático real acontece face a face, mediado por comunicação síncrona - telefone, web conferência, chat, etc. - ou assíncrona - fórum. No caso, diálogo didático simulado ocorre

1 Aretio, Lorenzo García. La educación a distância: de la teoria e la practica. Barcelona: Ariel Educación, 2001. 
pelo intermédio da mídia - material impresso, vídeos, áudios, etc. - ou seja, a comunicação está no texto escrito, narrado ou apresentado e a interpretação é do aluno, a partir do contato com este texto, sempre de forma assíncrona (FILATRO; CAIRO, 2015).

As autoras relatam que "desenvolver um conteúdo educacional é simular o diálogo didático real que será estabelecido entre professor (emissor) e seus alunos (receptores), adaptando o discurso oral e síncrono às especificidades das mídias assíncronas utilizadas" (FILATRO; CAIRO, 2015, p. 63).

Nesse sentido, seguem algumas descrições importantes referentes aos conteúdos educacionais: apresentá-los em uma linguagem clara, mais coloquial; indicar aos alunos as atividades que devem ser realizadas; promover reflexões; estimular os alunos a se envolverem com os conteúdos; reforçar a comunicação entre quem ensina e aprende utilizando pronomes pessoais e possessivos (FILATRO; CAIRO, 2015).

Azevedo e Souza (2010, p.8) apresentam algumas observações:

...durante o processo de desenvolvimento do material didático do curso, a colaboração, a responsabilidade, o desempenho, o respeito ao colega, o aprender a trabalhar em grupo, a dedicação e a cumplicidade entre os pares, tornam-se pontos cruciais para o sucesso de qualquer projeto pedagógico, especialmente na EaD.

Partindo daí, pode-se perceber que o maior desafio dos professores está em apresentar ou propor atividades autorais e compartilhadas que promovam a interação com os alunos. "Por mais experiente que seja o especialista em conteúdo, criar um recurso didático, seja ele um livro impresso ou um objeto de aprendizagem, não é a mesma coisa que dar uma aula, proferir uma palestra ou ministrar um curso" (FILATRO; CAIRO, 2015, p.280).

Nessa perspectiva, Silva (2011, p. 125) complementa: 
O assunto compartilhamento, naturalmente, abre espaço para outro: direitos autorais. Isso acontece porque estes constituem uma das maiores dificuldades enfrentadas por aqueles que encontram recursos digitais na Web ou em outras tecnologias, como CD e DVD.

Maia e Mattar (2007) destacam que no ensino presencial os professores criavam seus materiais didáticos e utilizavam em qualquer instituição de ensino, sendo que poderiam publicar esses materiais, recebendo royalties como autor. $\mathrm{Na}$ EaD, os mesmos professores criam os materiais, que podem transformar-se em um produto e dependerá do tipo de contrato de trabalho que terá com a instituição de ensino. "Afinal de contas, quem é o proprietário intelectual do material dos cursos, os professores ou a instituição? Antes, os professores não precisavam dividir os royalties de seu trabalho com as instituições, o que parece, agora estar mudando" (MAIA; MATTAR, 2007, p. 113).

$\mathrm{Na}$ legislação brasileira não existe uma lei específica que regulamente a utilização de materiais disponíveis na internet. Tanto as instituições de ensino como professores valem-se da Lei $n^{\circ}$ 9.610, de 19 de fevereiro de 1998, com as alterações sofridas pela Lei No 12.853 , de 14 de agosto de 2013, que consolida a legislação sobre direitos autorais e dá outras providências. No seu Art. $7^{\circ}$ consta que são "obras intelectuais protegidas as criações do espírito, expressas por qualquer meio ou fixadas em qualquer suporte, tangível ou intangível, conhecido ou que se invente no futuro" (BRASIL, 2013), tais como:

I - os textos de obras literárias, artísticas ou científicas;

II - as conferências, alocuções, sermões e outras obras da mesma natureza;

III - as obras dramáticas e dramático-musicais;

IV - as obras coreográficas e pantomímicas, cuja execução cênica se fixe por escrito ou por outra qualquer forma; $\mathrm{V}$ - as composições musicais, tenham ou não letra;

VI - as obras audiovisuais, sonorizadas ou não, inclusive as cinematográficas; 
VII - as obras fotográficas e as produzidas por qualquer processo análogo ao da fotografia;

VIII - as obras de desenho, pintura, gravura, escultura, litografia e arte cinética;

IX - as ilustrações, cartas geográficas e outras obras da mesma natureza;

$\mathrm{X}$ - os projetos, esboços e obras plásticas concernentes à geografia, engenharia, topografia, arquitetura, paisagismo, cenografia e ciência;

XI - as adaptações, traduções e outras transformações de obras originais, apresentadas como criação intelectual nova; XII - os programas de computador;

XIII - as coletâneas ou compilações, antologias, enciclopédias, dicionários, bases de dados e outras obras, que, por sua seleção, organização ou disposição de seu conteúdo, constituam uma criação intelectual.

Outra legislação utilizada é a Lei n 9.609, de 19 de novembro de 1998, Lei do Software ou programa de computadores, que estabelece regras próprias para a proteção do criador do software, "que é tecnicamente entendido como um conjunto de componentes e programas empregados para instruir uma máquina (hardware) e realizar atividades específicas e delineadas pelos seres humanos" (RICARDO; DIAS, 2012, p. 456).

Prosseguindo com Filatro e Cairo (2015, p. 285),

Em linhas gerais, os direitos autorais incidem sobre produtos concretos: textos, ilustrações, fotografias, áudios, vídeos etc., mas não se aplicam a ideias ou pensamentos, e são divididos em direito moral (autoria propriamente dita) e direito patrimonial (direito à reprodução e distribuição).

No entanto, a legislação brasileira não prevê todos os casos possíveis para utilização de materiais didáticos, no que se refere aos direitos autorais. "Assim, os advogados costumam trabalhar com analogias quando os casos não estão previstos em Lei" 
(PIVA; AMORIM, 2012, p. 342). Por este ângulo, Mesquita, Piva Jr. e Gara (2014, p. 105) ponderam que,

Ao se verificar as legislações que tratam dos direitos autorais, numa visão geral, o que podemos notar implicitamente é a isenção dos educadores para a utilização justificada de certas obras intelectuais (pequenos trechos) em sua sala de aula. Ou seja, os professores não têm a necessidade de obter permissão dos proprietários dos direitos autorais para utilizar esses pequenos trechos em sala de aula.

Nesta lógica, na EaD torna-se prudente utilizar obras de terceiros que sejam distribuídas por Creative Commons ${ }^{2}$ (CC) ou estejam em Domínio Público ${ }^{3}$, sendo que este é o principal portal com materiais didáticos abertos. Uma particularidade relevante é que são obras muito antigas, cujos autores já falecerem há mais de 70 anos e que são livremente reproduzidas e distribuídas.

Ainda, Piva Jr., Amorim e Rodrigues (2013, p. 86 apud MESQUITA; PIVA JR; GARA, 2014, p. 105) apontam que

No caso dos materiais didáticos produzidos em múltiplas mídias, como software, hipertextos ou vídeos, quase sempre podem ser vistos como materiais educacionais destinados ao trabalho acadêmico e sem fins lucrativos. Nestes casos, a lei permite o uso de partes de obras de terceiros, desde que tal uso não gere prejuízos aos detentores de direitos morais, autorais, patrimoniais e de distribuição.

Contribuindo para essa compreensão, Maia e Mattar (2007) nos esclarece que o sistema Creative Commons "procura combinar proteção com liberdade por meio da modificação do lema 'todos

Disponível em: <http://www.creativecommons.org>. Acesso em: 26/07/2018.

3 Principal portal no Brasil com material livre. Disponível em: <http://www. dominiopublico.gov.br>. Acesso em: 26/07/2018. 
os direitos reservados" " para "alguns direitos reservados", ou seja, alguns direitos são cedidos ao público enquanto outros são retidos pelos autores" (MAIA; MATTAR, 2007, p. 112), dependendo do contrato e da licença.

Para Filatro e Cairo (2015, p. 288),

Isso significa que os usuários podem copiar, traduzir e modificar recursos disponibilizados sob essa licença. Em geral, as restrições são de que a fonte original seja citada (direitos morais) e, comumente, que os materiais não sejam utilizados para fins comerciais (direitos patrimoniais).

Independentemente da situação, segundo Piva e Amorim (2012) deve-se citar a fonte do material utilizando as normas da Associação Brasileira de Normas Técnicas (ABNT), referenciando o autor, ano de publicação, página, etc. Nos casos da internet, inclui-se o endereço eletrônico e data de acesso.

Para utilização parcial ou total de uma obra, aconselha-se pedir autorização do autor, pois o "desrespeito a direitos autorais pode configurar-se em plágio - ou seja, a apresentação feita por alguém, como se fosse de sua autoria, de uma obra intelectual produzida por terceiros" (FILATRO; CAIRO, 2015, p. 287).

O Censo da EaD de 2015 (ASSOCIAÇÃO BRASILEIRA DE EDUCAÇÃO A DISTÂNCIA, 2016, p. 53) destaca que "as instituições apresentaram tendência a produzir seus conteúdos textuais de forma autônoma. Para todos os tipos de cursos, mais de $50 \%$ das instituições produziram seus próprios materiais" enquanto a terceirização foi utilizada por $44 \%$ das instituições que ofertaram cursos regulamentados totalmente a distância.

Diante dos fatos apresentados e das questões legais, as instituições de ensino e os cursos têm a tarefa de pensar as propostas educativas e a produção de materiais didáticos de forma conjunta e consciente, o que exige diálogo e parceria na construção desses materiais, pois na educação a distância as atividades não acontecem de forma solitária. Para que uma

4 Simbolizados pela marca de copyright, (C) (FILATRO; CAIRO, 2015).

Simbolizado pela marca de copyleft (FILATRO; CAIRO, 2015). 
aula se concretize, de fato, existe uma equipe multidisciplinar que trabalha para fomentar e criar propostas comprometidas com a essência filosófica da instituição e com o projeto político pedagógico. Azevedo e Olivério (2016, p. 21) argumentam que

...o desenvolvimento do trabalho na equipe multidisciplinar só alcança êxito quando de fato há diálogo e parceria, quando o professor, autor, permite compartilhar sua experiência docente na EaD com os demais agentes de equipe, e desta forma estabelece novas relações com o conhecimento e com os agentes do processo educativo. Professores, alunos e equipes multidisciplinares passam a ser desafiados numa dinâmica de produção de conhecimento em rede, compartilhado, com autoria, fundamentado em pesquisa.

Nesse sentido, a tarefa fundamental dos gestores dos cursos é orientar sua equipe docente a respeito dos direitos autorais e de como devem produzir seus materiais para ministrar a aula na modalidade, possibilitando assim a formação continuada dos professores. Um caminho possível é por meio da “....assessoria pedagógica e equipe de produção. Ambas trabalhando juntas para a melhoria constante dos materiais didáticos digitais, produzidos semanalmente no âmbito de cada um dos cursos EaD da instituição" (AZEVEDO; OLIVÉRIO, 2016, p. 19).

Ademais, pela complexidade de todas essas colocações, as instituições de ensino precisam especificar sua política de direitos autorais e os professores autores devem conferir os detalhes dos contratos antes de assiná-los.

\section{CONSIDERAÇÕES FINAIS}

A consciência dos profissionais que atuam na EaD, seu reconhecimento e sua legitimação por meio de políticas de qualidade vêm ganhando força e alterando a forma de concepção desse tipo de ensino em um mundo contemporâneo e globalizado. É um trabalho que avança dentro da linha de formação de educadores, partindo de reflexões e ações, uma vez que quanto 
maior for a intencionalidade de interação na proposta, maior a necessidade de planejamento para as intervenções pedagógicas.

O sistema educacional passa a ter como desafio atender à demanda de uma sociedade globalizada e que se organiza incorporando as TDIC nos currículos dos cursos, nas propostas avaliativas e na forma de se comunicar e interagir com o uso de ferramentas. "Os AVAs devem estar bem configurados, de acordo com o interesse e objetivos pedagógicos propostos nas matrizes curriculares e por todos os envolvidos" (AZEVEDO, 2013, p. 168).

$\mathrm{Na}$ realização deste estudo, evidenciaram-se as discussões sobre o planejamento, que nos destina a ações previamente organizadas no AVA, para responder aos desafios da aprendizagem. Desse modo foi possível oportunizar a execução, o acompanhamento e a avaliação do ato educativo (FILATRO; CAIRO, 2015) - ou seja, um bom planejamento de curso reverbera em boas propostas de formação discente e condução das mesmas.

Nessa perspectiva, há que se levar em consideração o gerenciamento do tempo, a possibilidade de o docente colocar-se no lugar do discente e, também, que sejam ponderadas as escolhas de conteúdos e atividades segundo uma intencionalidade pedagógica relevante e que não sobrecarregue o aluno. Concerne considerar, então, a importância do professor mediador, que orienta e dinamiza a aprendizagem, exercendo com intencionalidade ações estratégicas nas suas práticas pedagógicas ao realizar o seu planejamento de aulas (AZEVEDO, 2010).

Além disso, as reflexões que se desenvolveram até aqui a respeito da EaD consideraram os desafios contemporâneos da docência no século XXI, como a autoria docente, partindo do planejamento pedagógico e da produção de materiais didáticos, para redirecionar o olhar para uma educação a distância que tem se firmado como um caminho para consolidação democrática do ensino superior, com qualidade, no país.

\section{REFERÊNCIAS}

ASSOCIAÇÃO BRASILEIRA DE EDUCAÇÃO A DISTÂNCIA - ABED. Censo EAD.BR: Relatório Analítico da Aprendizagem a Distância no Brasil 
2015. Curitiba; InterSaberes, 2016.

AZEVEDO, Adriana Barroso. Aprendizagem na EaD: contribuições e desafios. Educação \& Linguagem, São Bernardo do Campo, v. 16, n. 27, p. 151-169, jan./jun. 2013. Disponível em: <https://www.metodista.br/revistas/revistas-ims/index.php/EL/article/viewFile/4003/3662>. Acesso em: 04 jun. 2018.

AZEVEDO, Adriana Barroso de; OLIVÉRIO, Marcio Araújo. Autoria e parceria na construção de materiais didáticos digitais na EaD. In: AZEVEDO, Adriana Barroso de (Orgs.). Caminhos da educação a distância: uma década de democracia, aprendizagem e experiência. São Bernardo do Campo: Universidade Metodista de São Paulo, 2016. p. 14-22.

AZEVEDO, Adriana Barroso de; SOUZA, Taís Rios Salomão de. Formação de professores em educação a distância: a experiência da Universidade Metodista de São Paulo. In: CONGRESSO INTERNACIONAL DE EDUCAÇÃO, 2., 2010, Ponta Grossa. Anais eletrônicos..., Ponta Grossa: CIEPG, 2010. Disponível em: <http://www.isapg.com.br/2010/ciepg/selecionados.php>. Acesso em: 04 jun. 2018.

BRASIL. Decreto $\mathrm{n}^{\circ}$ 9.057, de 25 de maio de 2017. Regulamenta o art. 80 da Lei $\mathrm{n}^{\circ}$ 9.394, de 20 de dezembro de 1996, que estabelece as diretrizes e bases da educação nacional. Diário Oficial da União, Brasília, 26 maio 2017. Seção 1, p. 1. Disponível em: <http://www2.camara.leg.br/legin/fed/decret/2017/ decreto-9057-25-maio-2017-784941-publicacaooriginal-152832-pe.html>. Acesso em: 04 de jun. de 2018.

BRASIL. Lei no 9.609, de 19 de fevereiro de 1998. Dispõe sobre a proteção da propriedade intelectual de programa de computador, sua comercialização no País, e dá outras providências. Diário Oficial da União, Brasília, 20 fev. 1998 [1998b]. Seção 1, p. 1. Disponível em: <http://www2.camara.leg.br/ legin/fed/lei/1998/lei-9609-19-fevereiro-1998-364738-norma-pl.html>. Acesso em: 04 jun. 2018.

BRASIL. Lei $n^{\circ}$ 9.610, de 19 de fevereiro de 1998. Altera, atualiza e consolida a legislação sobre direitos autorais e dá outras providências. Diário Oficial da União, Brasília, 20 fev. 1998 [1998c]. Seção 1, p. 3. Disponível em: <http:/ / www2.camara.leg.br/legin/ fed/lei/1998/lei-9610-19-fevereiro-1998-365399-norma-pl.html>. Acesso em: 04 jun. 2018.

BRASIL. Lei $\mathrm{n}^{\circ}$ 12.853, de 14 de agosto de 2013. Altera os arts. 5, 68, 97, 98, 99 e 100, acrescenta arts. 98-A, 98-B, 98-C, 99-A, 99-B, 100-A, 100-B e 109-A e revoga o art. 94 da Lei no 9.610, de 19 de fevereiro de 1998, para dispor sobre a gestão coletiva de direitos autorais, e dá outras providências. 
Diário Oficial da União, Brasília, 15 de ago. 2013, Seção 1, p. 1. Disponível em: <http://www2.camara.leg.br/legin/fed/lei/2013/lei-12853-14-agosto2013-776771-norma-pl.html>. Acesso em: 04 jun. 2018.

BEHAR, Patricia Alejandra. Modelos Pedagógicos em educação a distância. In: BEHAR, Patricia Alejandra (Org.). Modelos pedagógicos em Educação a Distância. Porto Alegre: Artmed, 2009. p. 15-32

CLEMENTINO, Adriana. Planejamento pedagógico para cursos EAD. In: KENSKY, Vani Moreira. Design instrucional para cursos on-line. São Paulo: Editora Senac São Paulo, 2015. p.151-190.

FILATRO, Andrea; CAIRO, Sabrina. Produção de Conteúdos Educacionais. São Paulo: Saraiva, 2015.

FREIRE, Paulo. Pedagogia da autonomia:saberes necessários a prática educativa. São Paulo: Paz e Terra, 1996. (Coleção Leitura).

MAIA, Carmem; MATTAR, João. ABC da EaD: a educação a distância hoje. São Paulo: Pearson Prentice Hall, 2007.

PIVA JR, Dilermando; AMORIM, Joni de Almeida. Direitos autorais em EAD. In: LITTO, Frederic Michael; FORMIGA, Manuel Marcos Maciel (Orgs.). Educação a Distância: o estado da arte, volume 2. São Paulo: Pearson Education do Brasil, 2012. p. 340-343.

MESQUITA, Deleni; PIVA JR, Dilermando; GARA, Elizabete Briani Macedo. Ambiente Virtual de Aprendizagem: conceitos, normas, procedimentos e práticas pedagógicas no ensino a distância. São Paulo: Érica, 2014.

MINISTÉRIO DA EDUCAÇÃO. SECRETARIA DE EDUCAÇÃO A DISTÂNCIA. Referenciais de Qualidade para Educação Superior a Distância. Brasília: MEC/SED, 2007. Disponível em: <http://portal.mec.gov.br/seed/ arquivos/pdf/legislacao/refead1.pdf $>$. Acesso em: 04 jun. 2018.

MINISTÉRIO DA EDUCAÇÃO. CONSELHO NACIONAL DE EDUCAÇÃO. CÂMARA DE EDUCAÇÃO SUPERIOR. Resolução CNE/CES $\mathrm{n}^{\circ} 1$, de 11 de março de 2016. Estabelece Diretrizes e Normas Nacionais para a Oferta de Programas e Cursos de Educação Superior na Modalidade a Distância. Diário Oficial da União, Brasília, 14 mar. 2016. Seção 1, p. 23 e 24. Disponível em: <http://www.semesp.org.br/legislacao/resolucao-cneces-n-1-de-11-de-marco-de-2016/>. Acesso em: 04 jun. 2018. 
RICARDO, Eleonora Jorge. Educação a Distância: professores-autores em tempos de cibercultura. São Paulo: Atlas, 2013.

RICARDO, Eleonora Jorge; DIAS, José Carlos Vaz. Questões relevantes do ensino a distância e seus efeitos (implicações) no direito da propriedade intelectual. In: SILVA, Marco Antonio (Org.). Educação Online. São Paulo: Edições Loyola, 2012. p. 453-462. SILVA, Robson Santos da. Gestão de EAD: Educação a distância na era digital. São Paulo: Novatec Editora, 2013.

SILVA, Robson Santos da. Objetos de aprendizagem para Educação a Distância. São Paulo: Novatec Editora, 2011.

\section{SOBRE A AUTORA}

Mestre em Educação pela Universidade Metodista de São Paulo - UMESP. Especialista em Educação a Distância e Docência no Ensino Superior. Graduada em Pedagogia. Atualmente, é docente no curso de Pedagogia a distância e na Pós-Graduação Alfabetização e Letramento presencial da UMESP. E-mail: regiane.faim@gmail.com. 